\title{
The Effect Of Garlic Consumption With Prescribed Anti-Platelet Medicines On Platelet Count Of Cardiovascular Patients
}

\author{
Sana Tariq ${ }^{1}$, Parveen Akhter ${ }^{2}$, Sidra Qayyum ${ }^{3}$, Fatima Khawar ${ }^{4}$ \\ ${ }^{1}$ Department of Public Health, Shaheed Zulfiqar Ali Bhutto University, Karachi, Pakistan \\ ${ }^{2}$ National Institute of Cardiovascular Diseases, Karachi, Pakistan \\ ${ }^{3}$ Ayub teaching hospital, Abbottabad, Pakistan \\ ${ }^{4}$ Department of Paediatric, District Head Quarters, University Medical and Dental College, Sargodha, \\ Pakistan
}

Received: April 15, 2021 Accepted: June 17, 2021

\begin{abstract}
INTRODUCTION: Garlic (A. sativum) is in use as a traditional medicine for millions of years. It is already establish that A. sativum is nature's best antibacterial, antiviral, antifungal, antiparasitic agent. Its helpful effects for Cardiovascular system, Blood, Immune system, Central Nervous system, Respiratory system, Anti-cancer, Anti-Inflammatory and Antidiabetic properties have already been studied. In this study, we will evaluate the effects of garlic consumption on platelets count of MI Patients along with other blood-thinning medicines. METHODS: This is a cross sectional study, 500 patients were interviewed. Interview questions included demographic information, diet plan, lifestyle, garlic consumption. $412(82.45 \%)$, patients stated that they are using or have used garlic for more than 6 months in raw form to reduce the symptoms of hypertension, along with prescribed medicines such as aspirin and clopidogrel. RESULTS: Platelet count of all patients of the study has been monitored and results showed $22.4 \%$ of them had thrombocytopenia with less than $150,000 \mathrm{mcL}$ platelet count while only $2.19 \%$ showed thrombocytosis high levels of platelets count in complete blood count. Patients reported symptoms of excessive fatigues, unexplained vaginal bleeding, easy bruising, extreme headache, fluctuating blood pressure and other related symptoms. Garlic has a really impressive and wide range of pharmacological properties including antimicrobial, anticancer, cardiovascular disease An amazing pharmacological agent like A. sativum may affect adversely if taken without precaution. CONCLUSION: High dosage of garlic results in intoxication and disturbance of platelet count. However, a careful measure should be taken before garlic consumption especially with other blood-thinning medicines.
\end{abstract}

Keywords: Garlic supplement, Platelet count, Thrombocytopenia, Combination therapy

*Correspondence: Sana Tariq, Department of Public Health, Shaheed Zulfiqar Ali Bhutto University, Karachi, Pakistan, Tel: 0092-317-2591939, Email: sanatariqrajput@gmail.com

\section{INTRODUCTION}

Garlic (A. sativum) has been used not only as a daily diet of Egyptians [1] but also as a traditional medicine for hundreds of years, [2]. Botanic name of A. sativum which belongs to Allium Family, was known to increase strength in human, used to feed to the labors, workers involved in building of Egyptian pyramids[3]. Father of the medicine, The great Hippocrates used garlic as a crucial part of his medicines, advocating that garlic is highly beneficial for pulmonary issues as well as uterine growths [4]. A few previously published studies recommended garlic for parasitosis, throat and fungal infections [5, 6]. In the last few decades, garlic has been studied for its immense beneficial properties of treating cardiovascular diseases [7], diabetes [8], anti-cancer [3] anti-aging effects [9]. Numerous studies have demonstrated the effects of garlic on Platelet aggregation [10] and cholesterollowering effects [11]. The Therapeutic effects of A. sativum are highly depended on the organosulfur components and their biochemical properties. The active compounds commonly found in garlic are Alliin, Allicin, Diallyl sulfide, Diallyl disulfide, Diallyl trisulfide, EAjoene, Z-Ajeone, S-allyl cysteine (SAC) and Thiacremonone[12] Fig 1. 
<smiles>C=CCSCC=C</smiles>

Diallyl sulfide (DAS)

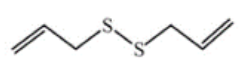

Diallyl disulfide (DADS)

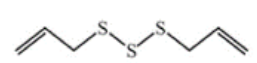

Diallyl trisulfide (DATS)

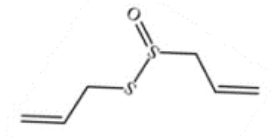

Allicin

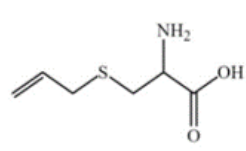

S-allyl-cysteine

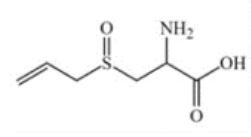

Alliin

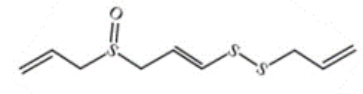

E-ajoene

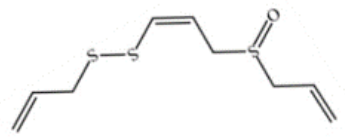

Z-ajoene

Fig 1: Different forms of $A$. sativum chemical composition.

All the functional compounds present in garlic, Alliin an amino acid cysteine derivative is the most abundant one, [12] The other compounds has the detailed functionality and pharmacokinetics of all the derived compounds of garlic. All these biochemical agents help garlic maintaining the image of the most widely used medicinal herb till date (Table 1)

Table 1: Pharmacological effects of A. sativum.

\begin{tabular}{|c|l|c|}
\hline Biologically active compound & Biological potential & References \\
\hline $\begin{array}{c}\text { Diallyl sulfide, Diallyl disulfide, } \\
\text { Diallyl trisulfide }\end{array}$ & Carcinopreventive & {$[13-15]$} \\
\hline Alliin & Carcinopreventive, Antioxidant & {$[15-18]$} \\
\hline Ajoenes & $\begin{array}{l}\text { Carcinopreventive, Antimicrobial, } \\
\text { Antithrombotic }\end{array}$ & {$[19-21]$} \\
\hline $1,2-$ Vinyldithiin & $\begin{array}{l}\text { Antithrombotic, Antioxident, } \\
\text { Antimicrobial }\end{array}$ & {$[22]$} \\
\hline
\end{tabular}

In developing countries, the prevalence of cardiovascular disease (CVD) such as stroke, coronary artery disease (CAD) and Angina is much higher. In 2017 cardiovascular disease was responsible for 176.8 million deaths globally [23]. WHO members committed to providing drug-related counselling to $50 \%$ of the population over 40 years of age by 2025 to reduce the risk of CVD[24]. In recent years, garlic has been a focus of attention because of its potential role in the prevention of various CVD [25] Several clinical trials with garlic and its biological components have been conducted all over the world. Most studies have shown lipid-lowering effects [26]. Garlic has known effect on platelets in humans; garlic extract inhibits binding of ADP-activated platelets to immobilized fibrinogen. In another study it was reported that the plasma viscosity and unstable angina can be decreased by garlic, while elastic property of vessels and capillary perfusion increases [27, 28]. Even though the garlic is an effective herb to prevent and treat a wide range of diseases, the study is lacking for garlic overdose or interaction with other hypertensive, blood-thinning medicines. As garlic is very effective for hypertension[29] and platelet aggregation[30], it mimics the pharmacological actions of Clopidogrel, a blood-thinning medicine used to prevent platelet aggregation in acute CVD. Simultaneous use of both garlic and Clopidogrel may cause 
inhibitory effect on platelets resulting in excessive blood thinning or improved platelet aggregation, forming a thrombus. In Pakistan people are more eager to get involved with herbal traditional treatment as compared to typical clinical investigation and prescriptions. This attitude leads them towards different herbal formulas to reduce their symptoms. Garlic has been used as a major herb in Pakistan for the prevention and treatment of hypertension and CVD, as well as to prevent heart attack; it is easily available and of low cost. Sufficient literature is not available on the following topic which needs for further investigations. This study is focusing on hypertensive patients, to evaluate the effects of combining garlic with prescribed antihypertensive medicines on platelet count and other related symptoms.

\section{MATERIALS AND METHOD:}

This is a cross-sectional, survey-based study, included 500 patients from the Inpatient department of Karachi Institute of Heart Diseases, from September 2018 to September 2019. Study was approved by ethical review board incharge of the center. All patients were above 18 years of age, and legally authorized to give consent. Informed consent was signed by every participant after explaining every aspect of data confidentiality and study perspective. The patients were categorized into two groups. Group I included the patients using prescribed medicines along with garlic formula (crushed garlic with honey and herbs) to reduce or cure cardiovascular problems, while group II comprised of patients using only prescribed medicines. Whole blood parameters were observed for platelet count evaluation and proper history of diet pattern, herbal medicines usage and other related symptoms were taken along with diagnosis at the time of admission, previous history of any surgery and medicines, comorbidities and symptoms were recorded. Patients were asked if they have taken the garlic formula for symptoms relive with their hypertensive medicines and did they experienced any kind of bleeding, discomfort, excessive bruising or any other related symptoms. Participants were also inquired if they felt better, relived after this combination therapy.

\section{RESULTS:}

The data set for this study comprised of patients with mean age of $58.15 \pm 11.6$ years. The ratio between male: female was 177: 323 , which makes $35.4 \%$ of male and $64.6 \%$ of female participants. Out of 500 patients, $412(82.45 \%)$ stated that they used garlic to reduce or cure hypertension and its symptoms along with the prescribed medicines by cardiologists. The prescribed medicines included Clopidogrel and aspirin with $75 \mathrm{mg}$ to $300 \mathrm{mg}$ and $75 \mathrm{mg}$ to $100 \mathrm{mg}$ strengths respectively. Chest pain was the most common presenting complain of 208 (51.6\%) patients while hypertension was the second most common complaint among 171 (34\%) of total patients. Respiratory issues were mentioned by $71(14.2 \%)$ patients. The diagnosis after initial investigations was ACS (acute coronary syndrome) in $378(75.6 \%)$ patients, Mean values of blood pressure, pulse rate, hemoglobin and random blood glucose levels recorded were $128.9 \pm 15.4 \mathrm{mmHg}, 80.5 \pm 10.4 / \mathrm{min}, 11.0 \pm 2.5 \mathrm{~g} / \mathrm{dL}$ and $178.5 \pm 78.9$ $\mathrm{mmol} / \mathrm{L}$ respectively. The Rationale of our study was to evaluate the effects on platelet count, the results showed $80(16 \%)$ patients using both prescribed medicines and garlic formula for more than 2 years with $<150,000$ mcL while only $32(6.4 \%)$ patients using just prescribed medicines without any kind of garlic formula showed the results of thrombocytopenia. Whereas, $11(2.19 \%)$ patients had a platelet count of $>450,000 \mathrm{mcL}$ or thrombocytosis and no patient of the group II showed thrombocytosis. Upon asking about related symptoms, only $03(0.6 \%)$ patients including 01 female and 02 males with thrombocytopenia, reported Unexplained bleeding from gums, vagina, and nose, while $16(3.2 \%)$ mentioned easy bruising without any specific trauma or blunt injury. While dizziness, palpitations and chest pain after exertion was mentioned by 75 (15\%), 34 (6.8\%) and 121 (24.2\%) respectively. Regarding the psychological satisfaction to the prescribed medicine or garlic formula, $121(24.2 \%)$ 
participants said that they were feeling much better after combining their medicines and garlic formula remedy, while 95 (19\%) said they didn't notice any relieve or improvement in their condition. (Table 2).

In order to eliminate the chances of biasness, the odds ratio analysis was performed, which indicated the positive association of garlic consumption with elevated blood pressure (1.6) and shortness of breath (2.4) while the risk estimation of thrombocytopenia has higher odds with $6.1 \%$ chances. (Table 3 )

\section{DISCUSSION:}

There are many factors associated with hypertension and other signs and symptoms of CVD. The majority of researches support the idea of garlic being helpful for avoiding platelet aggregation, reducing hypertension and eliminating the risk of cardiovascular issues. Although in recent years due to the changing dietary habit, stressful and sedentary lifestyle every cardiologist prescribe antiplatelet or antihypertensive medicines to patients showing mild symptoms of cardiovascular issues and in Pakistan using herbal medicines to reduce symptoms or diseases is highly prevalent. Due to its easy consumption and cost-effectiveness, people are more prone to use herbs than medicines. Garlic formula or raw garlic has been in use from last 2 decades among Pakistani population for eliminating the effects of hypertension, chest pain and lowering cholesterol levels. The complexity of garlic composition is immense and many studies have used different portions, formula, preparations of garlic to get their desired results, there are multiple mechanisms to inhibit platelet aggregation. Garlic may interact with other cardiovascular medicines such as clopidogrel, aspirin as well as antiplatelet, antihypertensive, calcium channel blockers and hypoglycaemic drugs and other medications[31]. Garlic, may also help in reducing lipid quantities of blood and may decrease the atherosclerosis process. However, with all its amazing and diverse advantages, A. sativum mimics the pharmacokinetics of antiplatelet medicines and patients who are on prescribed medicines for their platelet aggregation or hypertension may experience side effects and worsen of signs and symptoms after using garlic in combination with medicines. Its effect may lower the platelet count more extensively and results in thrombocytopenia, excessive unexplained bleeding and bruising. If not the limit, garlic along with antiplatelet medicines may affect patients as in this study many patients were admitted with acute chest pain after using the combination therapy for years. The active constituents of garlic, their bioavailability and drug interactions are important issues, which need to be addressed. CVD is ascending and garlic consumption is increasing the chances of making this issue of rising phenomena to think and work on. There should be some planned in vivo studies to evaluate the exact effects of garlic and antiplatelet medicines on platelet count of humans after a certain age, cardiovascular history is more important in this scenario.

\section{CONCLUSION:}

Therapeutic effects of Garlic (A. sativum) are been studied decades ago, the herb has immensely powerful preventive effect on many diseases and infections. Although the self medication may harm patients more than giving benefits. Our study concluded that taking Garlic (A. sativum) as self-medication along with prescribed blood thinning medicines may reduce platelets count and cause damage to the patients of cardiovascular diseases. The severity of CVS disease and old age are also associated with adverse outcomes of Garlic consumption with medicines. 
Biosight 2021; 02(01): 31-38

Table 02: Descriptive analysis of participants of Group A (Aspirin + Clopidogrel + garlic) and Group B (Aspirin + Clopidogrel):

\begin{tabular}{|c|c|c|c|c|}
\hline \multicolumn{2}{|c|}{ Variables } & \multirow{2}{*}{$\begin{array}{c}\begin{array}{c}\text { Garlic with Clopidogrel } \\
\text { and Aspirin combination } \\
\mathbf{n}=\mathbf{4 1 2}\end{array} \\
149(29.7 \%)\end{array}$} & \multirow{2}{*}{$\begin{array}{c}\begin{array}{c}\text { Clopidogrel and } \\
\text { Aspirin } \\
\mathbf{n = 8 8}\end{array} \\
22(4.3 \%)\end{array}$} & \\
\hline \multirow{3}{*}{$\begin{array}{l}\text { Presenting } \\
\text { Complain }\end{array}$} & Hypertension & & & \\
\hline & Chest Pain & $205(41 \%)$ & $53(10.6 \%)$ & \multirow[t]{2}{*}{0.1} \\
\hline & Respiratory Issues & $58(11.6 \%)$ & $13(2.6 \%)$ & \\
\hline \multirow{8}{*}{$\begin{array}{l}\text { Diagnosis At } \\
\text { the Time of } \\
\text { Admission. }\end{array}$} & $\begin{array}{l}\text { ACS (Acute } \\
\text { coronary } \\
\text { Syndrome) }\end{array}$ & $300(60 \%)$ & $78(15.6 \%)$ & \multirow{8}{*}{0.006} \\
\hline & $\begin{array}{l}\text { NSTEMI(Non- } \\
\text { ST-elevation MI) }\end{array}$ & $18(3.6 \%)$ & 0 & \\
\hline & ACS / HTN & $16(3.2 \%)$ & 0 & \\
\hline & ACS / NSTEMI & $24(4.8 \%)$ & 0 & \\
\hline & Ext. Wall MI & $16(3.2 \%)$ & 0 & \\
\hline & Inf. Wall MI & $8(1.6 \%)$ & 0 & \\
\hline & $\begin{array}{l}\text { Acute Pulmonary } \\
\text { Edema }\end{array}$ & $16(3.2 \%)$ & 0 & \\
\hline & $\begin{array}{l}\text { LVF ( Left } \\
\text { Ventricular } \\
\text { Failure) }\end{array}$ & $14(2.8 \%)$ & $2(0.4 \%)$ & \\
\hline \multirow{3}{*}{ Platelet Count } & $\begin{array}{l}\text { Normal Range } \\
(150,000- \\
450,000 \mathrm{mcL})\end{array}$ & $321(64.2 \%)$ & $56(11.2 \%)$ & \multirow{3}{*}{0.001} \\
\hline & $\begin{array}{l}\text { Thrombocytopeni } \\
\text { a }(<150,000 \mathrm{mcL})\end{array}$ & $80(16 \%)$ & $32(6.4 \%)$ & \\
\hline & $\begin{array}{l}\text { Thrombocytosis ( } \\
>450,000 \mathrm{mcL})\end{array}$ & $11(2.19 \%)$ & 0 & \\
\hline \multirow{6}{*}{ Side Effects } & $\begin{array}{c}\text { Unexplained } \\
\text { bleeding from } \\
\text { Gums, vagina, } \\
\text { nose }\end{array}$ & $3(0.6 \%)$ & $1(0.2 \%)$ & \multirow{6}{*}{0.0005} \\
\hline & Bruising & $16(3.2 \%)$ & $8(1.6 \%)$ & \\
\hline & Dizziness & $75(15 \%)$ & 0 & \\
\hline & Palpitations & $34(6.8 \%)$ & 0 & \\
\hline & Hypertension & $155(31 \%)$ & $24(4.8 \%)$ & \\
\hline & $\begin{array}{l}\text { Chest pain ( Mild, } \\
\text { Persistent after } \\
\text { exertion) }\end{array}$ & $121(24.2 \%)$ & $29(5.8 \%)$ & \\
\hline \multirow{3}{*}{$\begin{array}{l}\text { Psychological } \\
\text { satisfaction }\end{array}$} & Feeling better & $121(24.2 \%)$ & $24(4.8 \%)$ & \multirow{3}{*}{0.3} \\
\hline & Relieved & $496(99.2 \%)$ & $49(9.8 \%)$ & \\
\hline & Not good & $95(19 \%)$ & $15(3 \%)$ & \\
\hline
\end{tabular}


Biosight 2021; 02(01): 31-38

Table 3: Associated risk of adverse presenting complains with lower platelet counts in garlic consumption participants.

\begin{tabular}{|c|c|c|}
\hline \multirow{2}{*}{ Presenting complains } & Odds ratio \\
\cline { 2 - 3 } & Hypertension & $1.60 *(0.64-3.97)$ \\
\cline { 2 - 3 } & Chest Pain & $0.86(0.35-2.12)$ \\
\hline \multirow{2}{*}{ Platelet count } & Respiratory issues+ & $2.40 *(1.01-5.70)$ \\
\hline
\end{tabular}

ETHICS APPROVAL AND CONSENT TO PARTICIPATE

Not applicable.

HUMAN AND ANIMAL RIGHTS

Not applicable.

\section{CONSENT FOR PUBLICATION}

Not applicable.

\section{AVAILABILITY OF DATA AND MATERIALS}

None.

\section{FUNDING}

None.

\section{CONFLICT OF INTEREST}

The authors declare no conflict of interest, financial or otherwise.

\section{ACKNOWLEDGEMENTS}

None.

\section{REFERENCES:}

1. Block E. The chemistry of garlic and onions. Scientific american. 1985 Mar 1;252(3):114-21.

2. Agarwal KC. Therapeutic actions of garlic constituents. Medicinal research reviews. 1996 Jan;16(1):111-24.

El-Bayoumy K, Sinha R, Pinto JT, Rivlin RS. Cancer chemoprevention by garlic and garliccontaining sulfur and selenium compounds. The Journal of nutrition. 2006 Mar $1 ; 136(3): 864$ S-9S.

4. Farhat Z, Hershberger PA, Freudenheim JL, Mammen MJ, Blair RH, Aga DS, Mu L. Types of garlic and their anticancer and antioxidant activity: A review of the epidemiologic and experimental evidence. European Journal of Nutrition. 2021 Feb 4:1-25.

5. Rivlin RS. Historical perspective on the use of garlic. The Journal of nutrition. 2001 Mar;131(3):951S-4S.

6. Iciek M, Kwiecień I, Włodek L. Biological properties of garlic and garlic-derived organosulfur compounds. Environmental and molecular mutagenesis. 2009 Apr;50(3):24765 .

7. Yeh YY, Liu L. Cholesterol-lowering effect of garlic extracts and organosulfur compounds: human and animal studies. The journal of nutrition. $2001 \mathrm{Mar}$;131(3):989S-93S.

8. Eidi A, Eidi M, Esmaeili E. Antidiabetic effect of garlic (A. sativum L.) in normal and streptozotocin-induced diabetic rats. Phytomedicine. 2006 Nov 24;13(9-10):624-9. 
9. Rahman K. Historical perspective on garlic and cardiovascular disease. The journal of nutrition. 2001 Mar;131(3):977S-9S.

10. Bordia A. Effect of garlic on human platelet aggregation in vitro arun bordia. Atherosclerosis. 1978 Aug 1;30(4):355-60.

11. Warshafsky S, Kamer RS, Sivak SL. Effect of garlic on total serum cholesterol: a meta-analysis. Annals of internal medicine. 1993 Oct 1;119(7_Part_1):599-605.

12. Yun, H.-M., et al., Potential therapeutic effects of functionally active compounds isolated from garlic. 2014. 142(2): p. 183-195.

13. Singh, S.V., et al., Differential induction of NAD (P) H: quinone oxidoreductase by anti-carcinogenic organosulfides from garlic. 1998. 244(3): p. 917-920.

14. Srivastava, S.K., et al., Mechanism of differential efficacy of garlic organosulfides in preventing benzo (a) pyrene-induced cancer in mice. 1997. 118(1): p. 61-67.

15. Wattenberg, L.W., V.L. Sparnins, and G.J.C.r. Barany, Inhibition of Nnitrosodiethylamine carcinogenesis in mice by naturally occurring organosulfur compounds and monoterpenes. 1989. 49(10): p. 2689-2692.

16. Lim, S.-W., T.-H.J.K.J.o.F.S. Kim, and Technology, Physiological activity of alliin and ethanol extract from korean garlic (A. sativum, L.). 1997. 29(2): p. 348-354.

17. Steinmetz, K.A., et al., Vegetables, fruit, and colon cancer in the lowa women's health study. 1994. 139(1): p. 1-15.

18. Martins, N., S. Petropoulos, and I.C.J.F.c. Ferreira, Chemical composition and bioactive compounds of garlic (A. sativum L.) as affected by pre-and post-harvest conditions: A review. 2016. 211: p. 41-50.

19. Capasso, A.J.M., Antioxidant action and therapeutic efficacy of A. sativum L. 2013. 18(1): p. 690-700.

20. Harris, J., et al., Antimicrobial properties of A. sativum (garlic). 2001. 57(3): p. 282286.

21. Rahman, K.J.M.n. and f. research, Effects of garlic on platelet biochemistry and physiology. 2007. 51(11): p. 1335-1344.

22. Higuchi, O., et al., Antioxidative activity of sulfur-containing compounds in Allium species for human low-density lipoprotein (LDL) oxidation in vitro. 2003. 51(24): p. 72087214.

23. Roth, G.A., et al., Global, regional, and national age-sex-specific mortality for 282 causes of death in 195 countries and territories, 1980-2017: a systematic analysis for the Global Burden of Disease Study 2017. 2018. 392(10159): p. 1736-1788.

24. Organization, W.H., Global action plan for the prevention and control of noncommunicable diseases 2013-2020. 2013.

25. Qidwai, W., T.J.E.-B.C. Ashfaq, and A. Medicine, Role of garlic usage in cardiovascular disease prevention: an evidence-based approach. 2013. 2013.

26. Afzal, M., et al., Garlic and its medicinal potential. 2000. 8(2): p. 123-148.

27. Sumiyoshi, H. and M.J.J.C.R. Wargovich, Chemoprevention of 1, 2dimethylhydrazine-induced colon cancer in mice by naturally occurring organosulfur compounds. 1990. 50(16): p. 5084-5087.

28. Steiner, M. and R.J.J.o.c.p. Lin, Changes in platelet function and susceptibility of lipoproteins to oxidation associated with administration of aged garlic extract. 1998. 31(6): p. 904-908.

29. Cruz, C., et al., Renoprotective and antihypertensive effects of S-allylcysteine in 5/6 nephrectomized rats. 2007. 293(5): p. F1691-F1698.

30. Allison, G.L., G.M. Lowe, and K.J.T.J.o.n. Rahman, Aged garlic extract and its constituents inhibit platelet aggregation through multiple mechanisms. 2006. 136(3): p. 782S788 S. 
Biosight 2021; 02(01): 31-38

31. Hussein, H.J., et al., A Review: Anti-microbial, Anti-inflammatory effect and Cardiovascular effects of Garlic: A. sativum. 2017. 10(11): p. 4069-4078. 